\title{
Resumos de Teses
}

Espectroscopia de prótons por ressonância magnética do cérebro. Comparação das seqüências de voxel único PRESS e STEAM na avaliação de pacientes cirróticos.

Autor: Renato Adam Mendonça. Orientador: Jacob Szejnfeld.

Tese de Doutorado. Unifesp/EPM, 2005.

Objetivo: Avaliar as seqüências PRESS e STEAM em uma população definida de pacientes cirróticos, para confirmar e especificar correlações clínicas prévias e provar se a técnica PRESS pode fornecer os mesmos resultados quantitativos, com um tempo de aquisição reduzido em $50 \%$.

Métodos: Foram examinados 16 pacientes cirróticos confirmados por biópsia, escalados para transplante hepático, e 14 voluntários saudáveis em aparelho de ressonância magnética de 1,5 T para uso clínico. Os exames consistiram na obtenção de seqüências rotineiras de imagem para exame do encéfalo e na aquisição de quatro espectros do cérebro: duas aquisições repetitivas na substância cinzenta bioccipital e duas na substância branca parietal esquerda, respectivamente com as seqüências STEAM e PRESS.

Resultados: 0 estudo de reprodutibilidade foi positivo e significativo para as relações de mio-inositol (mlns), colina (Cho) e glutamina + glutamato (GIX) em ambas as seqüências. Em relação à capacidade de detectar $\mathrm{EH}$, os seguintes valores foram obtidos para ambas as seqüências: sensibilidade de $82,3 \%$, especificidade de $92 \%$ e acurácia de $86,85 \%$.

Conclusão: Os valores obtidos com ambas as seqüências foram similares àqueles previamente publicados com a utilização da seqüência STEAM na avaliação de pacientes cirróticos. Como a técnica PRESS fornece aproximadamente os mesmos resultados quantitativos, com redução do tempo de aquisição pela metade, esta seqüência deve ser o método de escolha para estudar espectros protônicos com TE curto. Os altos níveis de sensibilidade, especificidade e acurácia da concentração cerebral de GIx para diagnosticar EH sugerem que os metabólitos incluídos nesta faixa espectral possam se tornar marcadores importantes para o diagnóstico e manejo desta condição.

Estudo experimental da influência da filtração na dose de radiação e qualidade de imagens em raios-x de tórax pediátrico.

Autor: Renato Dimenstein.

Orientador: Henrique M. Lederman.

Tese de Mestrado. Unifesp/EPM, 2005.

Objetivo: Estudar a influência da filtração de fótons de raios- $X$ e sua correlação com a dose de radiação e a qualidade das imagens radiográficas.
Métodos: A verificação da influência da filtração foi aplicada aos estudos radiológicos do tórax pediátrico, por intermédio de um simulador antropomórfico equivalente a uma criança de cinco anos de idade, e com ferramentas de resolução (pares de linha por milímetro) e de contraste (escada de Al). As simulações foram realizadas em equipamento de raios- $X$ com filtração inerente $(2,5 \mathrm{mmAl})$, e com inserção de filtros adicionais de 2,0 mmAl, de 1,0 mmAl com $0,1 \mathrm{mmCu}$ e de $1,0 \mathrm{mmAl}$ com 0,2 $\mathrm{mmCu}$. As imagens radiográficas do simulador foram adquiridas com os diferentes filtros em modo manual e automático de exposição (AEC). Durante as simulações foram realizadas medidas de dose de radiação com pastilhas termoluminescentes (TLD), inseridas na entrada e dentro do simulador.

Resultados: Os resultados obtidos indicaram que a utilização da filtração adicional não alterou a resolução de imagens em termos de pares de linha/mm e possibilitou uma redução de dose de radiação de até $70 \%$ em comparação com a filtração inerente.

Conclusão: A utilização de filtração adicional de 1,0 mmAl com 0,2 mmCu apresentou a melhor relação entre dose de radiação e qualidade de imagens, atendendo-se assim o princípio de otimização de dose preconizado pelo ALARA. 